\title{
Effects of Exogenous Arachidonic, Eicosapentaenoic, and Docosahexaenoic Acids on the Generation of 5-Lipoxygenase Pathway Products by lonophore-activated Human Neutrophils
}

Tak H. Lee, Jean-Michel Mencia-Huerta, Chuan Shih, E. J. Corey, Robert A. Lewis, and K. Frank Austen Department of Medicine, Harvard Medical School, and Department of Rheumatology and Immunology, Brigham and Women's Hospital, Boston, Massachusetts 02115; Department of Chemistry, Harvard University, Cambridge, Massachusetts 02138

bstract. Exogenous eicosapentaenoic acid (EPA) and docosahexaenoic acid (DCHA) have been compared with exogenous arachidonic acid for their capacity to modulate the oxidative metabolism of membrane-derived arachidonic acid by the 5-lipoxygenase pathway in ionophore-activated human neutrophils and for their suitability as parallel substrates in this pathway. The products from specific ${ }^{14} \mathrm{C}$ - or ${ }^{3} \mathrm{H}$-labeled substrates were isolated by reverse phase high performance liquid chromatography (RP-HPLC) and were identified by elution of radiolabel at the retention times of the appropriate synthetic standards. Each product was also characterized by its ultraviolet (UV) absorption spectrum, and 7-hydroxy-DCHA was defined in addition by analysis of its mass spectrum. The metabolites, 5-hydroxyeicosatetraenoic acid, leukotriene $\mathrm{B}_{4} \quad\left(\mathrm{LTB}_{4}\right)$, 6-trans- $\mathrm{LTB}_{4}$ diastereoisomers, 5-hydroxyeicosapentaenoic acid, 6-trans-leukotriene $B_{5}$ diastereoisomers, leukotriene $\mathrm{B}_{5}\left(\mathrm{LTB}_{5}\right)$, and 7-hydroxy-DCHA were quantitated by integrated UV absorbance during resolution by RP-HPLC. $\mathrm{LTB}_{4}$ and $\mathrm{LTB}_{5}$ were also quantitated by

Dr. Lee is a recipient of a Saltwell Research Fellowship from the Royal College of Physicians, London. Dr. Mencia-Huerta is a Research Fellow of the Institut National de la Santé et de la Recherche Médicale, France, and partly supported by the Ministère de l'Industrie et de la Recherche.

Address reprint requests to Dr. Austen, Seeley G. Mudd Building, Room 604, 250 Longwood Avenue, Boston, MA 02115. 1984.

Received for publication 16 May 1984 and in revised form 2 August

J. Clin. Invest.

(c) The American Society for Clinical Investigation, Inc.

$0021-9738 / 84 / 12 / 1922 / 12 \$ 1.00$

Volume 74, December 1984, 1922-1933 radioimmunoassay of the eluate fractions, and leukotrienes $\mathrm{C}_{4}$ and $\mathrm{C}_{5}\left(\mathrm{LTC}_{4}\right.$ and $\mathrm{LTC}_{5}$, respectively) were quantitated by radioimmunoassay alone. None of the unlabeled exogenous fatty acids $(5-40 \mu \mathrm{g} / \mathrm{ml})$ altered the release of radioactivity from $\left[{ }^{14} \mathrm{C}\right]$ arachidonic acidlabeled, ionophore-activated neutrophils. The metabolism of 5 and $10 \mu \mathrm{g} / \mathrm{ml}$ of exogenous EPA by ionophoreactivated, $\left[{ }^{14} \mathrm{C}\right]$ arachidonic acid-labeled neutrophils not only generated 5-hydroxyeicosapentaenoic acid, 6-trans$\mathrm{LTB}_{5}, \mathrm{LTB}_{5}$, and $\mathrm{LTC}_{5}$, but also stimulated the formation of 5-hydroxyeicosatetraenoic acid, 6-trans-LTB diastereoisomers, and $\mathrm{LTC}_{4}$ from membrane-derived arachidonic acid. In contrast, $\mathrm{LTB}_{4}$ production was diminished throughout the EPA dose-response, beginning at $5 \mu \mathrm{g} / \mathrm{ml}$ EPA and reaching $50 \%$ suppression at 10 $\mu \mathrm{g} / \mathrm{ml}$ and $84 \%$ suppression at $40 \mu \mathrm{g} / \mathrm{ml}$. The selective decrease in extracellular $\mathrm{LTB}_{4}$ concentrations in the presence of EPA was not due to a change in the kinetic appearance of $\mathrm{LTB}_{4}$ or to an increase in conversion to its $\omega$-oxidation metabolites. DCHA was metabolized to 7-hydroxy-DCHA, did not stimulate metabolism of membrane-derived arachidonic acid, did not appreciably inhibit $\mathrm{LTB}_{4}$ formation, and was not a substrate for leukotriene formation. Incremental doses of exogenous arachidonic acid resulted in increased production of 5-hydroxyeicosatetraenoic acid and 6-trans-LTB $\mathrm{LB}_{4}$ by ionophore-activated, $\left[{ }^{14} \mathrm{C}\right]$ arachidonic acid-labeled neutrophils without any change in $\mathrm{LTB}_{4}$ production. 5hydroxyeicosapentaenoic acid and 7-hydroxy DCHA were inactive as chemotactic factors whereas 5-hydroxyeicosatetraenoic acid exhibited $2 \%$ of the potency of $\mathrm{LTB}_{4}$. Thus, exogenous DCHA does not appreciably interfere with the metabolism of membrane-derived arachidonic acid by ionophore-activated, $\left[{ }^{14} \mathrm{C}\right]$ ara- 
chidonic acid-labeled neutrophils and is converted only to a monohydroxy derivative. In contrast, exogenous EPA attenuates the generation of $\mathrm{LTB}_{4}$ and is converted to $\mathrm{LTB}_{5}$, which is a weak and partial agonist as compared with $\mathrm{LTB}_{4}$.

\section{Introduction}

The oxidative metabolism of arachidonic acid (AA), ${ }^{1}$ released from membrane phospholipids during cell activation, occurs by the cyclooxygenase pathway in many cell types (1) and by the 5-lipoxygenase pathway in cells involved in host inflammatory responses, such as human neutrophil polymorphonuclear leukocytes (PMNs) (2), eosinophils (3), monocytes (4), alveolar macrophages $(5,6)$, and mast cells $(7,8)$. 5-Lipoxygenase acts on AA to generate $5 S$-hydroperoxy-6-trans-8,11,14cis-eicosatetraenoic acid, which is reduced to $5 S$-hydroxy-6trans-8,11,14-cis-eicosatetraenoic acid (5-HETE) (9) or is converted to 5,6-oxido-7,9-trans-11,14-cis-eicosatetraenoic acid (leukotriene $\left.\mathrm{A}_{4}, \mathrm{LTA}_{4}\right)(10-12)$. $\mathrm{LTA}_{4}$ is converted by an epoxide hydrolase to $5 S, 12 R$-dihydroxy-6,14-cis-8,10-trans-eicosatetraenoic acid (leukotriene $\mathrm{B}_{4}, \mathrm{LTB}_{4}$ ) (13) or by a glutathione-S-transferase to $5 S$-hydroxy-6R-S-glutathionyl-7,9-trans11,14-cis-eicosatetraenoic acid (leukotriene $\mathrm{C}_{4}, \mathrm{LTC}_{4}$ ) (14). $\mathrm{LTA}_{4}$ also undergoes nonenzymatic hydrolysis to the diastereoisomers $5 S, 12 R$ - and $5 S, 12 S$-dihydroxy-6,8,10-trans-14-cis-eicosatetraenoic acid $\left[(5 S, 12 R)\right.$ - and $(5 S, 12 S)-6-$ trans- $\mathrm{LTB}_{4}$, respectively] and to minor products, the 5,6-dihydroxyeicosatetraenoic acid diastereoisomers (9).

Eicosapentaenoic acid (EPA) and its natural hydrocarbon chain extension and desaturation product, docosahexaenoic acid (DCHA), which are prominent in diets enriched with fish oil, competitively inhibit the conversion of AA to prostaglandins. In preparations of intact human platelets and of ram seminal vesicle microsomal-derived prostaglandin synthetase, both EPA and DCHA are poor substrates and compete with AA for conversion by cyclooxygenase (15-17). Furthermore, the prostaglandin endoperoxides and thromboxane $A_{3}$ derived

1. Abbreviations used in this paper: $\lambda_{\max }$, wavelength of maximum ultraviolet absorbance; $A_{234}$ and $A_{269}$, absorbance at 234 and $269 \mathrm{~nm}$, respectively; AA, arachidonic acid; DCHA, docosahexaenoic acid; 7 HDCHA, 7-hydroxy-DCHA; EPA, eicosapentaenoic acid; HBSS-BSA, HBSS-containing $30 \mathrm{mM}$ Hepes and $0.1 \%$ bovine serum albumin; 5 HEPE, 5-hydroxyeicosapentaenoic acid; 5-HETE, 5-hydroxyeicosatetraenoic acid; hpf, high power fields; HPLC, high-performance liquid chromatography; $\mathrm{ID}_{50}, 50 \%$ inhibition of binding; $\mathrm{LTA}_{4}, \mathrm{LTA}_{5}, \mathrm{LTB}_{4}$, $\mathrm{LTB}_{5}, \mathrm{LTC}_{4}, \mathrm{LTC}_{5}, \mathrm{LTD}_{4}, \mathrm{LTD}_{5}, \mathrm{LTE}_{4}$, and $\mathrm{LTE}_{5}$, leukotrienes $\mathrm{A}_{4}$, $A_{5}, B_{4}, B_{5}, C_{4}, C_{5}, D_{4}, D_{5}, E_{4}$, and $E_{5}$, respectively; rac-LTC $C_{5}$, racemic leukotriene $\mathrm{C}_{5}$; rac-5-HEPE, racemic 5-hydroxyeicosapentaenoic acid; RIA, radioimmunoassay; RP-HPLC, reverse phase-high-performance liquid chromatography; solvent I, $65 \%$ methanol $/ 34.9 \%$ water $/ 0.1 \%$ acetic acid (vol/vol, pH 5.6); solvent II, $75 \%$ methanol/24.9\% water/ $0.1 \%$ acetic acid (vol/vol, pH 5.6); solvent III, $100 \%$ methanol; solvent IV, $58 \%$ methanol/41.9\%/water/0.1\% acetic acid (vol/vol, pH 5.6); UV, ultraviolet. from EPA by the cyclooxygenase pathway are substantially less active than their AA-derived counterparts for eliciting aggregation of human platelets (15). With respect to products of the 5-lipoxygenase pathway, leukotriene $B_{5}\left(L_{T} B_{5}\right)$, the 5,12-dihydroxy derivative of EPA formed from leukotriene $A_{5}$ (LTA $)$, is a weak and partial agonist as compared with LTB $_{4}$ (18-21) in eliciting chemotactic and aggregating responses of human PMNs. The sulfidopeptide pentaene leukotrienes are equiactive with their tetraene counterparts $(20,22,23)$.

The effects of exogenous AA, EPA, and DCHA on ionophore-activated human PMNs have now been compared and EPA and DCHA are shown to differ in their capacity to regulate utilization of endogenous $\mathrm{AA}$ by the 5-lipoxygenase pathway. EPA metabolism is associated with preferential inhibition of $\mathrm{LTB}_{4}$ generation from membrane-derived AA and with conversion to chemotactically inactive 5-hydroxyeicosapentaenoic acid (5-HEPE) or attenuated LTB $_{5}$. DCHA has only minimal effects on the metabolism of cell membranederived AA by the 5-lipoxygenase cascade and is itself converted only to 7-hydroxy-DCHA (7-HDCHA), which has no chemotactic activity for human neutrophils. Thus, exogenous EPA and DCHA inhibit the metabolism of AA by the cyclooxygenase pathway (15-17), and EPA also suppresses the generation of $\mathrm{LTB}_{4}$ by the 5-lipoxygenase cascade. In addition, the major products of each alternative substrate have negligible or attenuated chemotactic activity.

\section{Methods}

Hanks' balanced salt solution (HBSS) (Microbiological Associates, Inc., Bethesda, MD); Ficoll-Hypaque and macromolecular dextran (Pharmacia Fine Chemicals, Uppsala, Sweden); $N$-2-hydroxyethyl-piperazine$N^{\prime}$-2-ethane sulfonic acid (Hepes) (Gibco Laboratories, Gibco Div., Grand Island, NY); calcium ionophore A23187 (Calbiochem-Behring Corp., La Jolla, CA); high performance liquid chromatography (HPLC)grade methanol (Burdick \& Jackson Laboratories, Inc., HoffmannLaRoche, Inc., Muskegon, MI); AA (Sigma Chemical Co., St. Louis, $\mathrm{MO})$; and $\left[{ }^{14} \mathrm{C}\right] \mathrm{AA}(55 \mathrm{mCi} / \mathrm{mmol}),\left[{ }^{14} \mathrm{C}\right] \mathrm{EPA}(55 \mathrm{mCi} / \mathrm{mmol})$, $\left[{ }^{3} \mathrm{H}\right]$ docosahexaenoic methylester $(4.0 \mathrm{Ci} / \mathrm{mmol}),\left[{ }^{3} \mathrm{H}\right] \mathrm{LTB}_{4} \quad(40$ $\mathrm{Ci} / \mathrm{mmol})$, and $\left[{ }^{3} \mathrm{H}\right] \mathrm{LTC}_{4}(36 \mathrm{Ci} / \mathrm{mmol})$ (New England Nuclear, Boston, MA) were obtained as noted. Eicosapentaenoic acid and DCHA were prepared as described (17) and shown to be $>99.8 \%$ pure by gas chromatography and $270-\mathrm{mHz}$ proton nuclear magnetic resonance spectroscopy. Each synthetic fatty acid was stored under argon in benzene at $-70^{\circ} \mathrm{C}$ and a sample was evaporated to dryness and resuspended in HBSS before use. Synthetic 5-HETE, $\mathrm{LTB}_{4},(5 S, 12 R)$ and $(5 S, 12 S)$-6-trans-LTB ${ }_{4}, \mathrm{LTC}_{4},(5 R, 6 S) \mathrm{LTC}_{4}$, leukotrienes $\mathrm{D}_{4}$ and $\mathrm{E}_{4}\left(\mathrm{LTD}_{4}\right.$ and $\mathrm{LTE}_{4}$, respectively), rac-5-HEPE (a racemic mixture of 5S-hydroxy-6-trans-8,11,14,17-cis-eicosapentaenoic acid and its diastereoisomer, $5 R$-hydroxy-6-trans-8,11,14,17-cis-eicosapentaenoic acid), $\mathrm{LTB}_{5},(5 S, 12 R)$ - and $(5 S, 12 S)$-6-trans-LTB , $_{5}$ and rac-LTC (a racemic $^{-}$ mixture of $\mathrm{LTC}_{5}$ and its diastereoisomer, $5 R$-hydroxy- $6 S$-glutathionyl7,9-trans-11,14,17-cis-EPA), and 4-hydroxydocosahexaenoic acid were prepared as previously described $(17,24-30)$ and stored at $-70^{\circ} \mathrm{C}$ in $0.1 \mathrm{M}$ phosphate buffer ( $\mathrm{pH} \mathrm{6.5)}$ containing 20\% (vol/vol) ethanol until use. A $0.25-\mathrm{nmol}$ sample of $\left[{ }^{3} \mathrm{H}\right]$ docosahexaenoic methylester $(1$ $\mu \mathrm{Ci})$ was hydrolyzed to its free acid by its addition to $200 \mu$ l of cold 
methanol/10 N NaOH (9:1, vol/vol) and standing at $4^{\circ} \mathrm{C}$ for $3 \mathrm{~h} \mathrm{(31);}$ the solvent was evaporated under a stream of nitrogen, and the residue was resuspended in ethanol and stored at $-70^{\circ} \mathrm{C}$ until use.

Preparation, $\left[{ }^{14} \mathrm{C}\right] A A$-labeling, and activation of PMNs. Human PMNs, obtained from citrate-anticoagulated blood, were purified to $>95 \%$ by dextran sedimentation, centrifugation through Ficoll-Hypaque, and hypotonic lysis of erythrocytes (32). The PMNs were washed three times in HBSS and suspended at a concentration of $1 \times 10^{7} / \mathrm{ml}$ in HBSS containing $30 \mathrm{mM}$ Hepes and $0.1 \%$ bovine serum albumin (HBSS-BSA). $1 \mathrm{ml}$ of the PMN suspension was incubated with 0.1 $\mu \mathrm{Ci}\left[{ }^{14} \mathrm{C}\right] \mathrm{AA}(1.8 \mathrm{nmol})$ for $60 \mathrm{~min}$ at $37^{\circ} \mathrm{C}$. A $50-\mu 1$ sample of the PMN suspension was removed, and the remaining PMNs were washed three times in HBSS-BSA and resuspended at a concentration of $1 \times 10^{7} / \mathrm{ml}$ in HBSS-BSA. $50 \mu \mathrm{l}$ of the initial PMN suspension in $\left[{ }^{14} \mathrm{C}\right] \mathrm{AA}$, of a pool of the supernatants from the three washes, and of the washed, labeled PMN suspension were each added separately to $10 \mathrm{ml}$ of scintillation fluid (Hydrofluor; National Diagnostics, Inc., Advanced Applications Institute Inc., Somerville, NJ), and the radioactivity was measured in a liquid $\beta$-scintillation counter (Mark III; Tracor Analytic Inc., Elk Grove Village, IL). More than $70 \%$ of the radiolabel was incorporated into the PMN preparations.

$10 \times 10^{6}\left[{ }^{14} \mathrm{C}\right] \mathrm{AA}-$ labeled PMNs in $500 \mu$ l HBSS-BSA were warmed to $37^{\circ} \mathrm{C}$ for $5 \mathrm{~min}$, mixed with $250 \mu \mathrm{l}$ of prewarmed, unlabeled AA, EPA, or DCHA, and activated by calcium ionophore A23187 dissolved in $250 \mu \mathrm{l}$ of HBSS-BSA containing $0.4 \%$ dimethylsulfoxide; final concentrations were $0-40 \mu \mathrm{g} / \mathrm{ml}$ for fatty acid and $10 \mu \mathrm{M}$ for ionophore. The mixtures were incubated at $37^{\circ} \mathrm{C}$ for $5 \mathrm{~min}$, and the reactions were stopped by rapid cooling at $4^{\circ} \mathrm{C}$ and centrifugation at $10,000 \mathrm{~g}$ for $30 \mathrm{~s}$. $50 \mu \mathrm{l}$ of the supernatant from each sample was added to 10 $\mathrm{ml}$ scintillation fluid and the radioactivity was measured. The remainder of the supernatants were stored under argon at $-20^{\circ} \mathrm{C}$ until resolution of reaction products by reverse phase-high performance liquid chromatography (RP-HPLC). Each cell pellet was suspended in $1 \mathrm{ml}$ HBSS-BSA and sonicated at $4^{\circ} \mathrm{C}$ with a sonifier (setting 3,40\% pulse cycle, 20 pulses; Branson Sonic Power Co., Danbury, CT); a 50- $\mu$ l sample of each sonicate was added to $10 \mathrm{ml}$ scintillation fluid and the radioactivity was measured. The percent release of incorporated radiolabel from each reaction mixture was calculated as: [(counts per minute in supernatant)/(counts per minute in supernatant + counts per minute in companion cell pellet)] $\times 100$. Cell viability in the absence or presence of $0-40 \mu \mathrm{g} / \mathrm{ml} \mathrm{AA}$, EPA, or DCHA was assessed by release of lactic dehydrogenase, which was consistently $<3 \%$.

Identification of PMN products by RP-HPLC. Products from each reaction mixture were applied to a $10-\mu \mathrm{m} \mathrm{C}_{18}$ Ultrasil-ODS column $(4.6 \times 250 \mathrm{~mm})$ (Altex Scientific, Inc., Berkeley, CA). The column was eluted at a flow rate of $1 \mathrm{ml} / \mathrm{min}$ with the following three-solvent program which resolves dihydroxy leukotrienes and monohydroxy fatty acids: $65 \%$ methanol $34.9 \%$ water $/ 0.1 \%$ acetic acid, vol/vol $\mathrm{pH}$ 5.6 (solvent I) for $\mathbf{3 0} \mathrm{min}$; then, after a step gradient over $0.2 \mathrm{~min}$ with $75 \%$ methanol $/ 24.9 \%$ water $/ 0.1 \%$ acetic acid, $\mathrm{pH} 5.6$ (solvent II), isocratically to $55 \mathrm{~min}$; and finally after a step gradient over $0.2 \mathrm{~min}$ with $100 \%$ methanol (solvent III), isocratically to $70 \mathrm{~min}$. 1-ml fractions were collected, and absorbance was continuously monitored at 269 $\mathrm{nm}\left(\mathrm{A}_{269}\right)$ during elution in solvent $\mathrm{I}$, and at $234 \mathrm{~nm}\left(\mathrm{~A}_{234}\right)$ during elution in solvents II and III with an on-line spectrophotometer (model 100-40; Hitachi, Ltd., Tokyo) linked to a Hewlett-Packard Integrator (model 3380A; Hewlett-Packard Co., Avondale, PA). The RP-HPLC program was calibrated for the retention times of synthetic standards: $(5 S, 12 R)-6$-trans $-\mathrm{LTB}_{5}(12.7 \pm 0.33 \mathrm{~min}$, mean $\pm \mathrm{SD}, n=4)$; $(5 S, 12 S)$ 6-trans-LTB 5 (13.5 $\pm 0.25 \mathrm{~min}, n=4)$; $\mathrm{LTB}_{5}(15.6 \pm 0.51 \mathrm{~min}, n=4)$;
$(5 S, 12 R)$-6-trans-LTB ${ }_{4}(19.3 \pm 0.67 \mathrm{~min}, n=4) ;(5 S, 12 S)$-6-trans-LTB $\mathrm{LT}_{4}$ (20.4 $\pm 0.9 \mathrm{~min}, n=4)$; $\mathrm{LTB}_{4}(25 \pm 1.1 \mathrm{~min}, n=4)$; rac-5-HEPE $(44.1 \pm 2$ min, $n=4)$; 5 -HETE $(50.8 \pm 2.9 \mathrm{~min}, n=4)$; [ $\left.{ }^{14} \mathrm{C}\right]$ EPA $(60.5 \mathrm{~min}$, mean, $n=2)$; $\left[{ }^{14} \mathrm{C}\right] \mathrm{AA}(62.1 \mathrm{~min}$, mean, $n=2)$; and $\left[{ }^{3} \mathrm{H}\right] \mathrm{DCHA}(65.7$ min, mean, $n=2$ ).

In experiments in which the quantities of tetraene and pentaene sulfidopeptide leukotrienes were also measured, the reaction products were separately resolved isocratically with $58 \%$ methanol/41.9\% water/ $0.1 \%$ acetic acid (vol/vol, $\mathrm{pH} 5.6$ ) (solvent IV). 1-ml fractions were collected and absorbance was continuously monitored at $269 \mathrm{~nm}$. The retention times of the synthetic standards in solvent IV were rac$\mathrm{LTC}_{5}, 18.8 \mathrm{~min} ; \mathrm{LTB}_{5}, 30.1 \mathrm{~min} ; \mathrm{LTC}_{4}, 30.1 \mathrm{~min} ; \mathrm{LTD}_{4}, 49.0 \mathrm{~min}$; $\mathrm{LTB}_{4}, 50.9 \mathrm{~min}$; and $\mathrm{LTE}_{4}, 57 \mathrm{~min}$.

$\omega$-Oxidation products of $\mathrm{LTB}_{4}$ were prepared for use as reference standards by incubation of $\left[{ }^{3} \mathrm{H}\right] \mathrm{LTB}_{4}(1.7 \mathrm{pmol})$ with $1 \times 10^{7} / \mathrm{ml}$ PMNs in the presence of $10 \mu \mathrm{M}$ calcium ionophore A23187 at $37^{\circ} \mathrm{C}$ for $15 \mathrm{~min}$. The cells were sedimented at $10,000 \mathrm{~g}$ for $30 \mathrm{~s}$ at room temperature and the labeled products in the supernatants were resolved by RP-HPLC in solvent I. In two experiments a mean of $91.5 \%$ of the added counts was recovered after RP-HPLC, and of these, 93.8\% eluted with an average retention time of $6.4 \mathrm{~min}$, consistent with that for $\omega$-oxidation products of $\mathrm{LTB}_{4}$ as chromatographed in a comparable solvent system $(33,34) ; 4.4 \%$ of the recovered counts eluted at the retention time of synthetic $\mathrm{LTB}_{4}(25 \mathrm{~min})$. When $\left[{ }^{3} \mathrm{H}\right] \mathrm{LTB}_{4}$ was incubated at $37^{\circ} \mathrm{C}$ for $15 \mathrm{~min}$ in HBSS without PMNs, a mean of $89 \%$ of the added counts was recovered after RP-HPLC, and of these, $91.5 \%$ eluted at the retention time of $\mathrm{LTB}_{4}$ and $<1 \%$ of the counts at the retention time of the $\omega$-oxidation products.

Quantitation of products. Products were quantitated by integrated ultraviolet (UV) absorbance and by radioactive and immunochemical measurements in fractions of defined retention times on RP-HPLC. The quantities of each product recovered from RP-HPLC were calculated using the integrated UV absorbance value obtained with known quantities of the appropriate synthetic standard; for 7-HDCHA it was necessary to employ 5-HETE as the standard. After RP-HPLC of each sample from $\left[{ }^{14} \mathrm{C}\right] \mathrm{AA}$-labeled PMNs, $10 \mathrm{ml}$ of scintillation fluid was added to each fraction and the radioactivity was measured. More than $76 \%$ of the radioactive counts applied was recovered from RP-HPLC for each experiment.

In selected experiments $1 \times 10^{7}$ unlabeled PMNs were activated by $10 \mu \mathrm{M}$ calcium ionophore $\mathrm{A} 23187$ at $37^{\circ} \mathrm{C}$ for $5 \mathrm{~min}$ in a final volume of $1 \mathrm{ml}$ of HBSS-BSA in the presence of $0.1 \mu \mathrm{Ci}\left[{ }^{14} \mathrm{C}\right] \mathrm{EPA}$ and $20 \mu \mathrm{g}$ unlabeled EPA $(66 \mu \mathrm{M})$, or of $0.1 \mu \mathrm{Ci}\left[{ }^{3} \mathrm{H}\right] \mathrm{DCHA}$ and 20 $\mu \mathrm{g}$ unlabeled DCHA $(61 \mu \mathrm{M})$. The reactions were stopped by rapid cooling to $4^{\circ} \mathrm{C}$ and centrifugation at $10,000 \mathrm{~g}$ for $30 \mathrm{~s}$. Each supernatant was resolved by RP-HPLC and the products were quantitated by integrated UV absorbance and by radioactivity of the eluted fractions; $>81 \%$ of the radioactive counts applied was recovered from RP-HPLC for each experiment.

For immunoassay of $\mathrm{LTB}_{4}$ and $\mathrm{LTB}_{5}, 5-\mu 1$ samples of the fractions were collected after RP-HPLC, and for immunoassay of the sulfidopeptide leukotrienes, $100-\mu l$ samples of the same fractions were evaporated to dryness under reduced pressure. The residues were resuspended

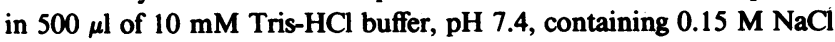
and $0.1 \%$ gelatin (Isogel Tris buffer), and $100 \mu \mathrm{l}$ of each mixture was assessed by radioimmunoassay. The standard curve for the inhibition binding of $\left[{ }^{3} \mathrm{H}\right] \mathrm{LTB}_{4}$ to anti-LTB $\mathrm{TB}_{4}$ antibody (35) was linear over a dose range of 0.1-5 ng and 0.01-1.0 ng for synthetic LTB $_{4}$ and LTB $_{5}$, respectively; $50 \%$ inhibition of binding $\left(\mathrm{ID}_{50}\right)$ of $\mathrm{LTB}_{4}$ and $\mathrm{LTB}_{5}$ occurred at $0.18 \mathrm{ng}$ and $0.06 \mathrm{ng}$, respectively (19). The standard curve 
for the inhibition of binding of $\left[{ }^{3} \mathrm{H}\right] \mathrm{LTC} \mathrm{C}_{4}$ to anti- $\mathrm{LTC}_{4}$ antibody (36) was linear over the range of 0.01-5 $\mathrm{ng}$ for $\mathrm{LTC}_{4}$, its diastereoisomer $(5 R, 6 S) \mathrm{LTC}_{4}, \mathrm{LTD}_{4}, \mathrm{LTE}_{4}$, and rac-LTC $\mathrm{LT}_{5}$, the $\mathrm{ID}_{50}$ values for $\mathrm{LTC}_{4}$, $(5 R, 6 S) \mathrm{LTC}_{4}, \mathrm{LTD}_{4}, \mathrm{LTE}_{4}$, and $r a c-\mathrm{LTC}_{5}$ were $0.20,0.19,0.66,0.72$, and $0.15 \mathrm{ng}$, respectively; the $\mathrm{ID}_{50}$ estimated for authentic $\mathrm{LTC}_{5}$ was $0.15 \mathrm{ng}$ based on the relative immunoreactivity of $\mathrm{LTC}_{4}$ and its diastereoisomer. The $\mathrm{ID}_{50}$ values for leukotrienes $\mathrm{D}_{5}$ and $\mathrm{E}_{5}\left(\mathrm{LTD}_{5}\right.$ and $\mathrm{LTE}_{5}$, respectively) were derived from that of $\mathrm{LTC}_{5}$ based on the observed $\mathrm{ID}_{50}$ ratios for the members of the tetraene series (20).

Characterization of the monohydroxy products of EPA and DCHA. $35 \times 10^{7}$ and $55 \times 10^{7}$ PMNs purified from the blood of two normal donors were suspended in HBSS-BSA at a concentration of $1 \times 10^{7}$ cells $/ \mathrm{ml}$ and activated by $10 \mu \mathrm{M}$ calcium ionophore for $5 \mathrm{~min}$ at $37^{\circ} \mathrm{C}$ in the presence of $20 \mu \mathrm{g} / \mathrm{ml}$ EPA. The reactions were stopped by the addition of 4 vol of cold ethanol and rapid cooling to $4^{\circ} \mathrm{C}$. The mixtures were allowed to stand at $4^{\circ} \mathrm{C}$ for $1 \mathrm{~h}$ and the precipitates were removed by sedimentation at $1000 \mathrm{~g}$ for $15 \mathrm{~min}$ at room temperature. The supernatants were evaporated to dryness under reduced pressure and the residues were suspended in $2 \mathrm{ml}$ of solvent $\mathrm{I}$ for resolution by RP-HPLC. The fractions eluting in a UV absorbance peak in solvent II at the retention time of rac-5-HEPE were combined and the UV absorption spectrum was determined on a spectrophotometer (model 210; Varian Associates, Inc., Palo Alto, CA).

$37 \times 10^{7}$ and $40 \times 10^{7}$ PMNs purified from blood of two normal donors were suspended in HBSS-BSA at a concentration of $1 \times 10^{7}$ cells $/ \mathrm{ml}$ and were activated by $10 \mu \mathrm{M}$ calcium ionophore for $5 \mathrm{~min}$ at $37^{\circ} \mathrm{C}$ in the presence of $40 \mu \mathrm{g} / \mathrm{ml} \mathrm{DCHA}$. The reactions were stopped and the supernatants were processed as described for the EPA product. The RP-HPLC fractions corresponding to the UV absorbance peak of the single DCHA-derived product eluting in solvent II were combined and the UV absorption spectrum was determined. The product was sequentially converted to its methylester by a reaction with ethereal diazomethane and to its fully saturated trimethylsilylether derivative (31) for mass spectral analysis on a spectrometer (MS-50; Kratos Analytical Instruments, Ramsey, NJ) with a capillary gas chromatographic inlet after a $70 \mathrm{eV}$ electron impact.

Chemotactic activities of 5-HETE, 5-HEPE, and 7-HDCHA. 5-HETE, 5-HEPE, and 7-HDCHA were obtained by incubating 20$45 \times 10^{7} \mathrm{PMNs}$ at a concentration of $1 \times 10^{7} \mathrm{cells} / \mathrm{ml}$ with $20-40 \mu \mathrm{g} /$ $\mathrm{ml}$ of AA, EPA, or DCHA, respectively, in the presence of $10 \mu \mathrm{M}$ ionophore $\mathrm{A} 23187$ at $37^{\circ} \mathrm{C}$ for $5 \mathrm{~min}$, as described above for characterization of the latter two products. The purity of the products resolved in solvent II after RP-HPLC was confirmed by straight-phase HPLC after the compounds were converted to their methylesters by a reaction with ethereal diazomethane (31). The esters were applied to a Zorbax Sil column $(4.6 \mathrm{~mm} \times 25 \mathrm{~cm}$; DuPont Instruments, Wilmington, DE) in hexane/tetrahydrofuran $(15: 1, \mathrm{vol} / \mathrm{vol})$ and eluted at a flow rate of $2 \mathrm{ml} / \mathrm{min}$ with continuous monitoring of absorbance at $235 \mathrm{~nm}$. The methyl esters of 7-HDCHA, 5-HETE, and 5-HEPE eluted as single peaks at 17, 20, and $22 \mathrm{~min}$, respectively; identical retention times were obtained with synthetic reference standards for the latter two compounds.

The chemotactic activities of 5-HETE, 5-HEPE, and 7-HDCHA were compared with each other and with that of synthetic $\mathrm{LTB}_{4}$ over a concentration range from 1 to $1,000 \mathrm{nM}$ by use of PMNs from three normal donors in a microchemotaxis assay (37). As determined by UV absorbance, defined amounts of each PMN-derived monohydroxy fatty acid and synthetic $\mathrm{LTB}_{4}$ were evaporated to dryness under reduced pressure and suspended in HBSS containing $30 \mathrm{mM}$ Hepes, pH 7.4. 25- $\mu$ l samples of serial dilutions of each fatty acid were placed in the lower well of separate microchemotactic chambers, which were separated by a $3-\mu \mathrm{m}$ pore-size nitrocellulose filter from the upper well containing $50 \mu \mathrm{l}$ of $10^{7} \mathrm{PMNs} / \mathrm{ml}$ HBSS with $30 \mathrm{mM}$ Hepes, pH 7.4, with $0.4 \%$ ovalbumin. After incubation for $2 \mathrm{~h}$ at $37^{\circ} \mathrm{C}$, the filters were fixed, stained with hematoxylin-chromatrope, and mounted on glass slides. The cells were counted at a filter depth corresponding to the maximal migration of cells exposed to control buffer alone. Results were expressed as the average number of PMNs/5 high power fields (hpf) after correction for background migration. The experiments were performed in duplicate and the intra-assay coefficient of variation for duplicate filters was $<35 \%$.

\section{Results}

Effects of exogenous $A A, E P A$, and DCHA on the percent release of incorporated radiolabel from $\left[{ }^{14} C\right] A A$-labeled PMNs. The effects of $40 \mu \mathrm{g} / \mathrm{ml}$ of exogenous AA, EPA, or DCHA on the time-dependent percent release of radiolabel from ionophore-activated $\left[{ }^{14} \mathrm{C}\right] \mathrm{AA}$-labeled PMNs were compared with each other and with the percent release of radiolabel in the absence of any exogenous fatty acid. Less than $5 \%$ of the radioactivity was released without ionophore, in the presence and absence of AA, EPA, and DCHA by $5 \mathrm{~min}$, and no further release occurred for incubation periods of up to 15 $\mathrm{min}$. With ionophore activation the percent release of radiolabel increased to a plateau of $\sim 15 \%$ 5-10 min after cell activation in the absence and presence of unlabeled exogenous AA, EPA, and DCHA (Fig. 1). The release of incorporated radiolabel from PMNs after a 5-min incubation with the ionophore was not influenced by any concentration of fatty acid and was not significantly different among the fatty acids. Cells not incubated with ionophore in the presence of exogenous fatty acid released $<5 \%$ of incorporated radiolabel, regardless of the type of fatty acid or its concentration.

Identification and characterization of the PMN 5-lipoxygenase pathway products derived from exogenous EPA. The oxidative metabolism of EPA by ionophore-activated PMNs was assessed in parallel reactions in which one set of $1 \times 10^{7}$ cells $/ \mathrm{ml}$ was unlabeled and activated in the presence of 0.1 $\mu \mathrm{Ci}\left[{ }^{14} \mathrm{C}\right]$ EPA and $20 \mu \mathrm{g} / \mathrm{ml}$ unlabeled EPA, and the other set from the same donor was radiolabeled with $\left[{ }^{14} \mathrm{C}\right] \mathrm{AA}$ and activated in the presence of $20 \mu \mathrm{g} / \mathrm{ml}$ unlabeled EPA (Fig. 2). Thus, it was possible to identify unlabeled membrane-derived AA products and both $\left[{ }^{14} \mathrm{C}\right] \mathrm{EPA}$-labeled and unlabeled products from exogenous EPA with the first set of cells $(B)$, and $\left[{ }^{14} \mathrm{C}\right] \mathrm{AA}$-labeled and unlabeled AA membrane-derived products and unlabeled products from exogenous EPA with the second set of cells $(C)$. As detected by integrated $A_{269}$ the products generated by both sets of cells eluted with the same retention times and thus only the pattern for the first set is depicted $(A)$. Products eluted in solvent $I$ as a single peak at 6.2 min distinct from the solvent front, as a doublet at 12.2 and $13.8 \mathrm{~min}$, as a single peak at $15.8 \mathrm{~min}$, as a doublet at 19.1 and $20.9 \mathrm{~min}$, and as a single peak at $26.1 \mathrm{~min}$. These retention times were identical to those of the reference standards for the $\omega$-oxidation 


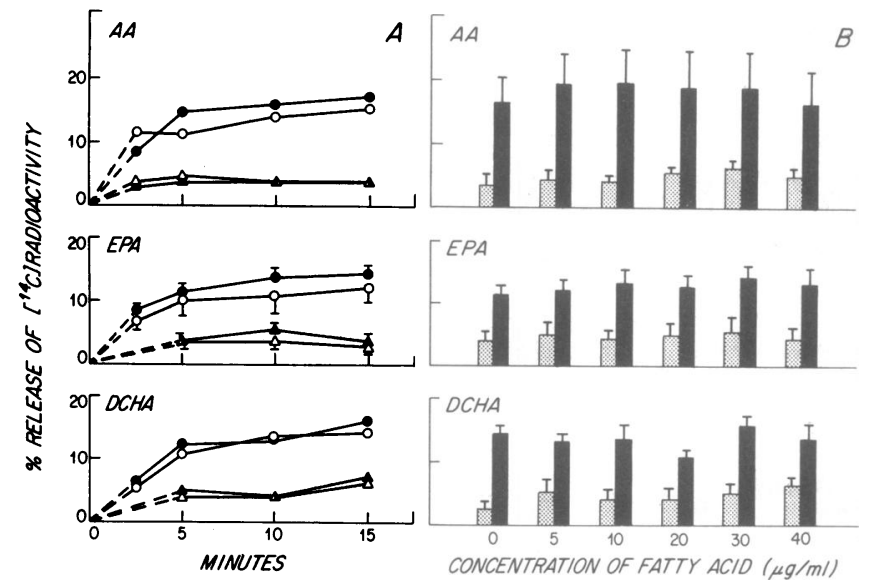

Figure 1. (A) The effects of exogenous AA, EPA, and DCHA (40 $\mu \mathrm{g} / \mathrm{ml})$ on the time-dependent release of radioactivity from $\left[{ }^{14} \mathrm{C}\right] \mathrm{AA}-$ labeled PMNs activated with ionophore A23187. PMNs $\left(1 \times 10^{7} / \mathrm{ml}\right)$ were incubated in buffer alone $(\Delta)$, with each fatty acid alone $(\Delta)$, with ionophore $(10 \mu \mathrm{M})$ alone (O), and with both ionophore and fatty acid (๑). The results for EPA are the mean \pm SEM of four experiments, and for AA and DCHA are the mean of two experiments. $(B)$ Dose-response effects of AA, EPA, and DCHA on the release of radioactivity from $\left[{ }^{14} \mathrm{C}\right] A A$-labeled PMNs $\left(1 \times 10^{7} / \mathrm{ml}\right)$ without (stippled bars) and with (solid bar) ionophore activation. The results are the mean \pm SEM of four experiments for AA and EPA and of three experiments for DCHA.

products of $\mathrm{LTB}_{4}$, 6-trans-LTB $\mathrm{TH}_{5}$ diastereoisomers, $\mathrm{LTB}_{5}$, 6-trans- $\mathrm{LTB}_{4}$ diastereoisomers, and $\mathrm{LTB}_{4}$, respectively. As monitored at $A_{234}$, two products eluted in solvent II at 41 and 50.2 $\mathrm{min}$, the respective retention times of the rac-5-HEPE and 5-HETE standards. Products eluting with the retention time of 6-trans-LTB $\mathrm{L}_{5}$ diastereoisomers, $\mathrm{LTB}_{5}$, and 5-HEPE incorporated radiolabel from $\left[{ }^{14} \mathrm{C}\right] \mathrm{EPA}$ only (Fig. $2, B$ ), and products eluting with the retention time of 6-trans-LTB $\mathrm{LB}_{4}$ diastereoisomers, $\mathrm{LTB}_{4}$, and 5-HETE incorporated radiolabel from $\left[{ }^{14} \mathrm{C}\right] \mathrm{AA}$ only (Fig. 2, C).

The more polar product obtained from 35 and $55 \times 10^{7}$ activated PMNs eluting at the retention time of synthetic rac5-HEPE in solvent II had its UV $\lambda_{\max }$ at $234.3 \mathrm{~nm}$ (mean, $n$ =2) which was identical to that of synthetic rac-5-HEPE (234.2 $\mathrm{nm}, n=2)$. The less polar product eluting at the retention time of synthetic 5-HETE had its $\lambda_{\max }$ at $234.8 \mathrm{~nm}$ (mean, $n=2$ ), as compared with that of synthetic 5-HETE, $234.6 \mathrm{~nm}$ (mean, $n=2$ ).

Effects of exogenous EPA on the generation of individual 5-lipoxygenase pathway metabolites from EPA and endogenous $A A$. The time-dependent generation of $\mathrm{LTB}_{4}$ and $\mathrm{LTB}_{5}$ from $1 \times 10^{7}\left[{ }^{14} \mathrm{C}\right] \mathrm{AA}$-labeled PMNs, activated by ionophore in the absence and presence of $40 \mu \mathrm{g} / \mathrm{ml}$ EPA, was measured by $A_{269}$, radioactive counts, and radioimmunoassay (RIA) and was maximal at $5 \mathrm{~min}$ for each product by each assay (Fig. 3). The generation of $\mathrm{LTB}_{4}$ in the absence of EPA was maximal

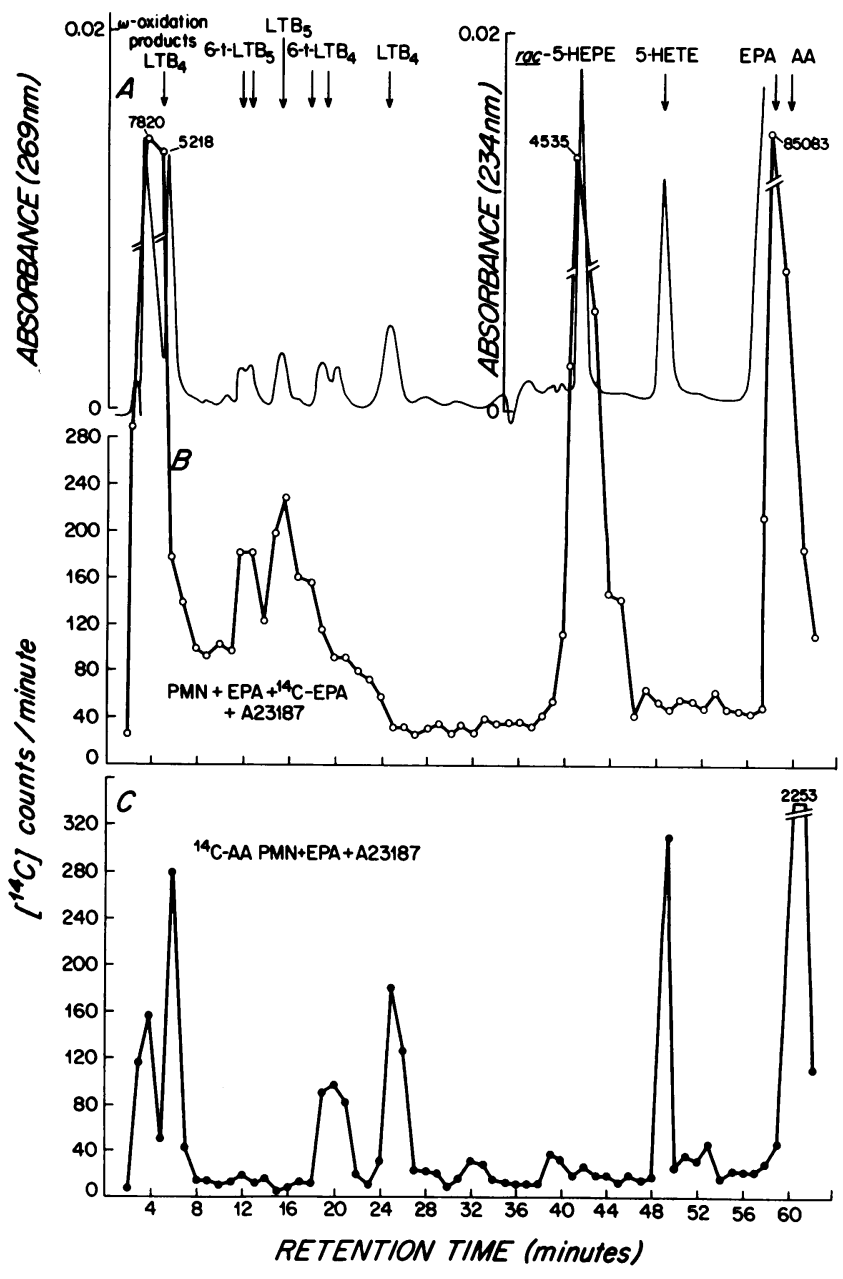

Figure 2. RP-HPLC of supernatants from PMNs $\left(1 \times 10^{7}\right.$ cells $\left./ \mathrm{ml}\right)$ activated with ionophore in the presence of $\left[{ }^{14} \mathrm{C}\right] \mathrm{EPA}(0.1 \mu \mathrm{Ci})$ and unlabeled EPA $(20 \mu \mathrm{g} / \mathrm{ml})$ analyzed by integrated UV absorbance $(A)$ and counts per minute $(O)(B)$, and of supernatants from $\left[{ }^{14} \mathrm{C}\right] \mathrm{AA}$ labeled PMNs $\left(1 \times 10^{7}\right.$ cells $\left./ \mathrm{ml}\right)$ activated with ionophore in the presence of unlabeled EPA $(20 \mu \mathrm{g} / \mathrm{ml})(\bullet)(C)$. The retention times of reference standards are indicated by the arrows. The counts per minute values in $B$ and $C$ that greatly exceed the scale on the ordinate are inserted on the plot itself at the relevant peaks, with the discontinuity of scale indicated by the interrupted lines to and from those points.

at $399 \pm 45 \mathrm{ng}$ (mean $\pm \mathrm{SEM}, n=4)$ by $\mathrm{A}_{269}$ and $480 \pm 30 \mathrm{ng}$ (mean \pm SEM, $n=3$ ) by RIA. In the presence of EPA the generation of $\mathrm{LTB}_{4}$ and $\mathrm{LTB}_{5}$ was $100 \pm 50$ and $192 \pm 21 \mathrm{ng}$ (mean \pm SEM, $n=4$ ), respectively, by $A_{269}$, and 125 and 275 $\mathrm{ng} / 10^{7}$ PMNs, respectively, by RIA, $5 \mathrm{~min}$ after cell activation.

$\left[{ }^{14} \mathrm{C}\right] \mathrm{AA}$-labeled PMNs $\left(1 \times 10^{7} / \mathrm{ml}\right)$ were activated by calcium ionophore in the absence and presence of increasing exogenous concentrations of EPA, and the products were resolved by RP-HPLC and quantitated by integrated UV absorbance (Fig. 4). The quantity of 5-HETE generated in the 

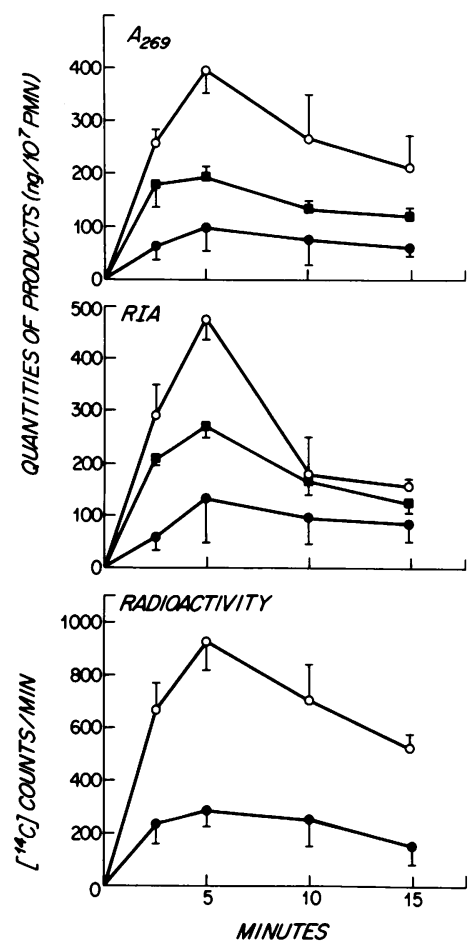

Figure 3. The time-dependent generation of $\mathrm{LTB}_{4}$ (O) in the absence of EPA, and of $\mathrm{LTB}_{4}(\bullet)$ and $\mathrm{LTB}_{5}$ $(\square)$ in the presence of 40 $\mu \mathrm{g} / \mathrm{ml}$ EPA from $\left[{ }^{14} \mathrm{C}\right] \mathrm{AA}-$ labeled PMNs $\left(1 \times 10^{7}\right.$ cells/ml) activated by 10 $\mu \mathrm{M}$ ionophore. The results quantitated by $A_{269}$ and radioactivity are the mean \pm SEM for four experiments, of which RIAs (mean \pm SEM) were performed in three.

absence of EPA, $334 \pm 226 \mathrm{ng}$ (mean $\pm \mathrm{SEM}, n=4$ ), increased with $5 \mu \mathrm{g} / \mathrm{ml}$ exogenous EPA and reached a maximum of $590 \pm 209 \mathrm{ng}($ mean \pm SEM, $n=4)$ at $10 \mu \mathrm{g} / \mathrm{ml} \mathrm{EPA}$; 5-HETE

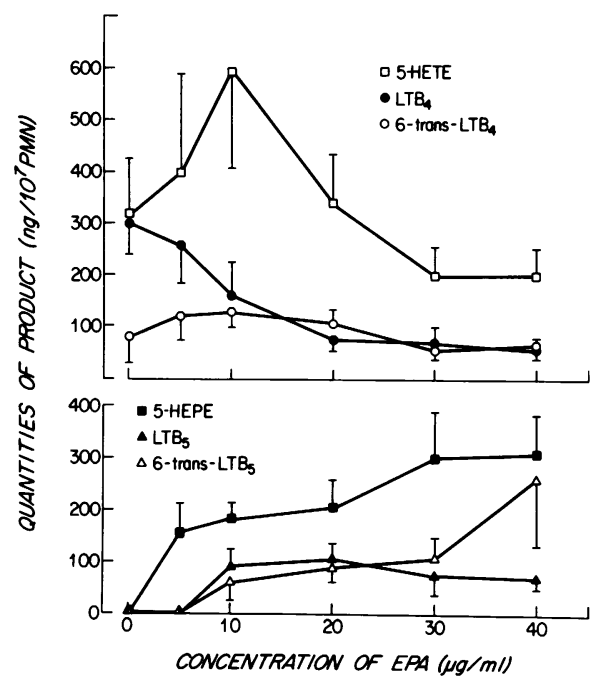

Figure 4. The effects of increasing concentrations of exogenous EPA on the generation by $\left[{ }^{14} \mathrm{C}\right] \mathrm{AA}-$ labeled PMNs $\left(1 \times 10^{7}\right.$ cells $\left./ \mathrm{ml}\right)$ activated with ionophore of 5-lipoxygenase pathway metabolites from cell membrane-derived AA (top) and exogenous EPA (bottom). The results, quantitated by UV absorbance, are mean \pm SEM of four experiments.

production fell to $200 \pm 56 \mathrm{ng}$ (mean $\pm \mathrm{SEM}, n=4)$ and $200 \pm 55$ ng (mean \pm SEM, $n=4$ ) at 30 and $40 \mu \mathrm{g} / \mathrm{ml} \mathrm{EPA,} \mathrm{respectively.}$ The 6-trans- $\mathrm{LTB}_{4}$ diastereoisomers, which totaled $80 \pm 53 \mathrm{ng}$ (mean \pm SEM, $n=4$ ) without EPA, rose to $131 \pm 36 \mathrm{ng}$ (mean \pm SEM, $n=4$ ) at $10 \mu \mathrm{g} / \mathrm{ml} \mathrm{EPA}$, and declined at higher EPA concentrations, such that only $61 \pm 8 \mathrm{ng}$ (mean $\pm S E M$, $n=4$ ) was generated in the presence of $40 \mu \mathrm{g} / \mathrm{ml} \mathrm{EPA}$. In contrast, there was no EPA-induced stimulation of $\mathrm{LTB}_{4}$ generation but rather there was a dose-dependent decrement in the quantities of $\mathrm{LTB}_{4}$ generated from $300 \pm 61 \mathrm{ng}$ (mean \pm SEM, $n=4$ ) in the absence of EPA to $49 \pm 12 \mathrm{ng} \mathrm{LTB}$ in the presence of $40 \mu \mathrm{g} / \mathrm{ml}$ EPA. The quantities of 5-HEPE and the 6-trans- $\mathrm{LTB}_{5}$ diastereoisomers increased in a doserelated manner with exogenous EPA to reach $311 \pm 73 \mathrm{ng}$ (mean \pm SEM, $n=4)$ and $260 \pm 215 \mathrm{ng}($ mean \pm SEM, $n=4)$ at $40 \mu \mathrm{g} / \mathrm{ml}$ EPA, respectively. The quantities of $\mathrm{LTB}_{5}$ increased to $102 \pm 35 \mathrm{ng}($ mean \pm SEM, $n=4)$ at $20 \mu \mathrm{g} / \mathrm{ml} \mathrm{EPA}$ and then decreased to $70 \pm 24 \mathrm{ng}$ (mean \pm SEM, $n=4$ ) at $40 \mu \mathrm{g} / \mathrm{ml}$ EPA.

For comparison, $1 \times 10^{7}\left[{ }^{14} \mathrm{C}\right] \mathrm{AA}$-labeled PMNs $\left(1 \times 10^{7} /\right.$ $\mathrm{ml}$ ) were activated with ionophore in the absence and presence of increasing concentrations of exogenous AA (Fig. $5 A$ ). Under these conditions, 5-HETE increased in a dose-related fashion from $157 \pm 76 \mathrm{ng}$ (mean \pm SEM, $n=4$ ) in the absence of exogenous AA to $950 \pm 225 \mathrm{ng}($ mean \pm SEM, $n=4)$ at 40 $\mu \mathrm{g} / \mathrm{ml} \mathrm{AA}$ and 6-trans- $\mathrm{LTB}_{4}$ increased from $52 \pm 50 \mathrm{ng}$ (mean \pm SEM, $n=4)$ to $400 \pm 105 \mathrm{ng}($ mean \pm SEM, $n=4)$ at $40 \mu \mathrm{g} / \mathrm{ml} \mathrm{AA}$. $\mathrm{LTB}_{4}$ increased insignificantly from $183 \pm 44 \mathrm{ng}$ (mean \pm SEM, $n=4$ ) in the absence of exogenous AA to a plateau of $220 \pm 51 \mathrm{ng}($ mean $\pm \mathrm{SEM}, n=4)$ at $5 \mu \mathrm{g} / \mathrm{ml} \mathrm{AA}$. In order to compare the dose-response effects of exogenous EPA

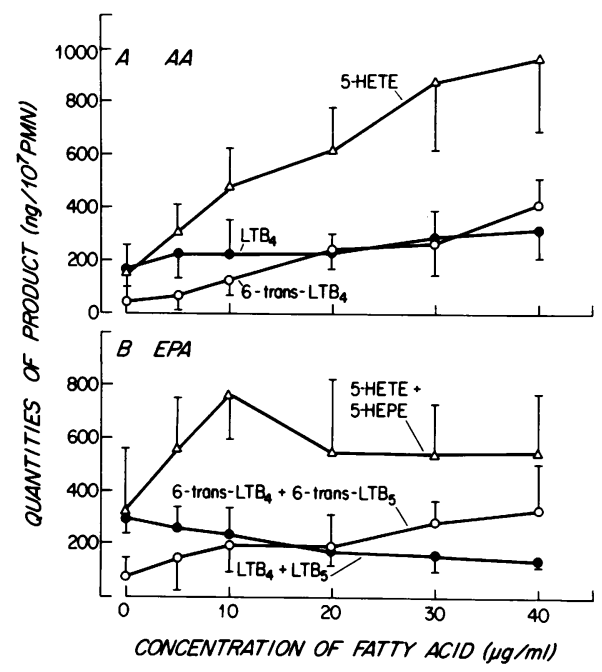

Figure 5. $(A)$ The effects of increasing exogenous concentrations of AA on product generation by $\left[{ }^{14} \mathrm{C}\right] \mathrm{AA}$-labeled PMNs $\left(1 \times 10^{7}\right.$ cells $/ \mathrm{ml}$ ) activated with ionophore. (B) Summation of the amounts of 5-HEPE and 5-HETE, $\mathrm{LTB}_{5}$ and $\mathrm{LTB}_{4}$, and 6-trans-LTB $\mathrm{L}_{5}$ and 6trans-LTB $\mathrm{L}_{4}$ from the data shown in the top and bottom of Fig. 4. 
with those of AA, the amounts of 5-HEPE and 5-HETE, LTB and $\mathrm{LTB}_{4}$, and 6-trans-LTB $\mathrm{LB}_{5}$ and 6-trans-LTB $\mathrm{LT}_{4}$ shown in Fig. 4 were summed at each dose of EPA (Fig. $5 B$ ). The generation of the monohydroxy fatty acids (5-HEPE and 5-HETE) increased from $334 \pm 226 \mathrm{ng}$ (mean $\pm \mathrm{SEM}, n=4$ ) in the absence of EPA to a peak of $760 \pm 155 \mathrm{ng}$ (mean \pm SEM, $n=4$ ) at 10 $\mu \mathrm{g} / \mathrm{ml} \mathrm{EPA}$ and fell to a plateau of $550 \mathrm{ng}$ at $20 \mu \mathrm{g} / \mathrm{ml}$ EPA. The quantities of 6-trans-LTB diastereoisomers (6-trans-LTB L $_{5}$ and 6-trans- $\mathrm{LTB}_{4}$ ) increased in a dose-dependent manner from $80 \pm 53 \mathrm{ng}$ (mean \pm SEM, $n=4$ ) without EPA to $321 \pm 176 \mathrm{ng}$ (mean \pm SEM, $n=4$ ) at $40 \mu \mathrm{g} / \mathrm{ml}$ EPA. The total quantities of LTB (LTB 5 and LTB $_{4}$ ) generated decreased in a dose-related fashion from $300 \pm 61 \mathrm{ng}$ in the absence of EPA to $119 \pm 16 \mathrm{ng}$ (mean \pm SEM, $n=4$ ) at $40 \mu \mathrm{g} / \mathrm{ml}$ EPA.

The marked reductions in quantities of $\mathrm{LTB}_{4}$ detected in the presence of increasing concentrations of EPA (Fig. 4) could have been due to decreased synthesis, increased $\omega$-oxidation, or both. Therefore, the radioactive counts originating from membrane-derived $\left[{ }^{14} \mathrm{C}\right] \mathrm{AA}$ and eluting with the $\omega$-oxidation products of $\mathrm{LTB}_{4}$ during RP-HPLC were compared with those eluting with $\mathrm{LTB}_{4}$. The sum of $\mathrm{LTB}_{4}$ and its $\omega$-metabolites increased to a plateau $5 \mathrm{~min}$ after cell activation, both in the absence and in the presence of EPA, with a continuing shift from $\mathrm{LTB}_{4}$ to $\omega$-metabolite(s) over the ensuing $10 \mathrm{~min}$ (Table I). As there was no significant difference in the percentage of total $\mathrm{LTB}_{4}$ measured as $\omega$-oxidation products at any time point in the presence and absence of EPA the reduced appearance of $\mathrm{LTB}_{4}$ was attributed to decreased synthesis.

In one experiment the products generated by $1 \times 10^{7}$ PMNs activated by $10 \mu \mathrm{M}$ ionophore for $5 \mathrm{~min}$ in the presence of increasing concentrations of EPA were resolved by RP-HPLC in solvent IV and quantitated by RIA and $A_{269}$

Table I. Kinetic Analysis of $\mathrm{LTB}_{4}$ and Its $\omega$-Metabolites Produced by $\left[{ }^{14} \mathrm{C}\right] \mathrm{AA}$-labeled PMNs $\left(1 \times 10^{7}\right.$ Cells $\left./ \mathrm{ml}\right)$ Activated with $10 \mu M$ Calcium Ionophore A23187 in the Absence and in the Presence of $40 \mu \mathrm{g} / \mathrm{ml} \mathrm{EPA*}$

\begin{tabular}{|c|c|c|c|c|}
\hline \multirow[b]{2}{*}{$\begin{array}{l}\text { Length of } \\
\text { incubation }\end{array}$} & \multicolumn{2}{|l|}{ No EPA } & \multicolumn{2}{|c|}{$40 \mu \mathrm{g} / \mathrm{ml}$ EPA } \\
\hline & Total $\mathrm{LTB}_{4}$ & $\begin{array}{l}\% \omega- \\
\text { metabolites } \$\end{array}$ & Total LTB $_{4}$ & $\begin{array}{l}\text { \% } \omega- \\
\text { metabolites }\end{array}$ \\
\hline $\min$ & cpm $\ddagger$ & & $c p m$ & \\
\hline 2.5 & $781 \pm 165$ & $23 \pm 5$ & $258 \pm 66$ & $20 \pm 3$ \\
\hline 5 & $1,033 \pm 395$ & $34 \pm 12$ & $404 \pm 44$ & $30 \pm 12$ \\
\hline 10 & $917 \pm 325$ & $55 \pm 22$ & $407 \pm 34$ & $50 \pm 22$ \\
\hline 15 & $1,010 \pm 282$ & $61 \pm 12$ & $376 \pm 40$ & $59 \pm 19$ \\
\hline
\end{tabular}

* The $\mathrm{LTB}_{4}$ and $\omega$-metabolites of $\mathrm{LTB}_{4}$ generated were resolved by RP-HPLC and quantitated in counts per minute; values are the mean $\pm S E M$ of four experiments.

‡ $\mathrm{LTB}_{4}$ and $\omega$-metabolites of $\mathrm{LTB}_{4}$.

$\S$ Percentage of total $\mathrm{LTB}_{4}$ as $\omega$-metabolites.

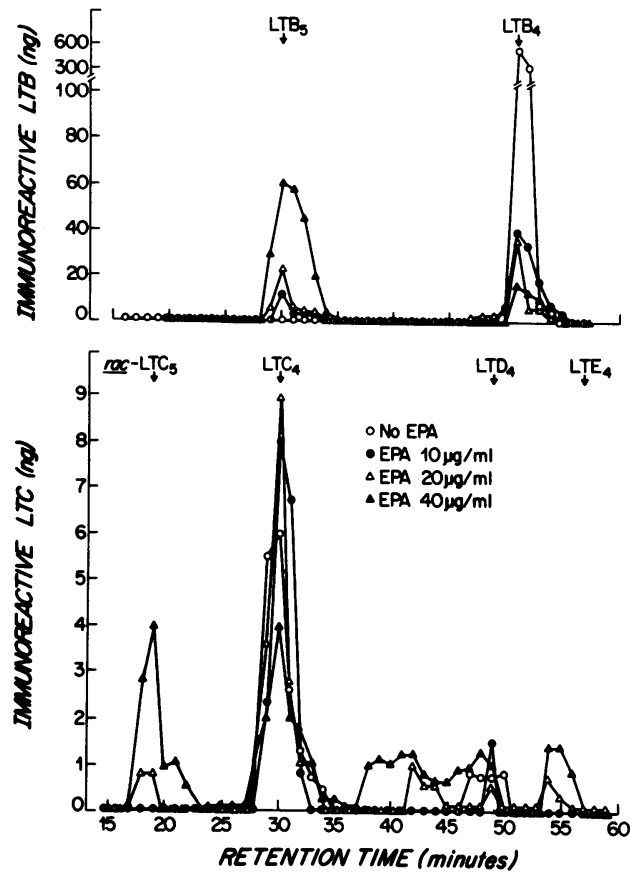

Figure 6. RP-HPLC of supernatants generated by PMNs $\left(1 \times 10^{7}\right.$ cells/ml) activated by ionophore in the absence and presence of increasing concentrations of EPA. The leukotriene concentrations of fractional eluates were measured by RIA. The retention times of synthetic reference standards have been indicated by the arrows.

(Fig. 6). In the absence of EPA, ionophore-activated PMNs produced $960 \mathrm{ng}$ of $\mathrm{LTB}_{4}$ by RIA and $925 \mathrm{ng}$ by $\mathrm{A}_{269}$, which eluted as one immunoreactive peak at the retention time of synthetic $\mathrm{LTB}_{4}(51 \mathrm{~min})$. With increasing concentrations of exogenous EPA, there was a dose-dependent decrease in the quantity of eluted immunoreactive $\mathrm{LTB}_{4}$ to $44 \mathrm{ng}$ by RIA and $55 \mathrm{ng}$ by $A_{269}$, at $40 \mu \mathrm{g} / \mathrm{ml}$ EPA. LTB $_{5}$, which eluted as one immunoreactive peak at the retention time of synthetic LTB $_{5}$ (30 min) increased in a dose-dependent manner to a maximum of $218 \mathrm{ng}$ by RIA and $196 \mathrm{ng}$ by $\mathrm{A}_{269}$ at $40 \mu \mathrm{g} / \mathrm{ml}$ EPA. In the absence of EPA, there was a predominant immunoreactive peak eluting at the retention time of synthetic $\mathrm{LTC}_{4}(30 \mathrm{~min})$ and a minor peak eluting as $\mathrm{LTD}_{4}(49 \mathrm{~min})$. With $40 \mu \mathrm{g} / \mathrm{ml}$ EPA, three additional immunoreactive products eluted at peak retention times of 19,41 , and $55 \mathrm{~min}$, respectively; the largest and most polar peak co-eluted with the rac-LTC $s$ standard; the two smaller peaks eluting just before the LTD 4 and $\mathrm{LTE}_{4}$ standards were presumed to be $\mathrm{LTD}_{5}$ and $\mathrm{LTE}_{5}$. In the absence of EPA a total of $18.1 \mathrm{ng}$ of sulfidopeptide leukotrienes were detected, of which $15 \mathrm{ng}$ was $\mathrm{LTC}_{4}$ representing $1.8 \%$ of the quantity of $\mathrm{LTB}_{4}$ measured in the same experiment. With increasing EPA concentrations, the quantities of $\mathrm{LTC}_{4}$ rose to $18 \mathrm{ng}$ at $10 \mu \mathrm{g}$ EPA and fell to $11 \mathrm{ng}$ with $40 \mu \mathrm{g}$ EPA, whereas $\mathrm{LTC}_{5}$ increased progressively to $9.3 \mathrm{ng}$ at $40 \mu \mathrm{g} / \mathrm{ml} \mathrm{EPA}$. The 
sum of $\mathrm{LTC}_{4}$ and $\mathrm{LTC}_{5}$ generated by $10^{7} \mathrm{PMNs}$ in the presence of increasing EPA concentrations exhibited an increment from $15 \mathrm{ng}$ in the absence of EPA to 18.0, 17.6, and $20.3 \mathrm{ng}$ at 10 , 20 , and $40 \mu \mathrm{g} / \mathrm{ml}$ EPA, respectively. The quantities of $\mathrm{LTC}_{4}$ plus $\mathrm{LTC}_{5}$ relative to $\mathrm{LTB}_{4}$ and $\mathrm{LTB}_{5}$ rose from $1.5 \%$ without EPA to $7.7 \%$ with $40 \mu \mathrm{g} / \mathrm{ml}$ EPA.

Because the quantities of tetraene sulfidopepide leukotrienes derived from $\mathrm{LTC}_{4}$ were minimal, whereas the $\mathrm{LTD}_{5}$ and LTE$_{5}$ were incompletely resolved by RP-HPLC and were estimated by an RIA without a specific standard, the quantitative effects of EPA on the sulfidopeptide leukotrienes are presented in terms of $\mathrm{LTC}_{4}$ and $\mathrm{LTC}_{5}$. The findings of a doserelated response of the pentaene sulfidopeptide leukotrienes to EPA would not be altered by the inclusion of the estimated values for the derivatives of LTC.

Identification and characterization of the PMN 5-lipoxygenase product derived from exogenous $D C H A$. The products of ionophore activation of $1 \times 10^{7}$ unlabeled PMNs, in the presence of $20 \mu \mathrm{g} / \mathrm{ml}$ exogenous unlabeled DCHA and 0.1 $\mu \mathrm{Ci} / \mathrm{ml}\left[{ }^{3} \mathrm{H}\right] \mathrm{DCHA} / \mathrm{ml}$ in two experiments were resolved by RP-HPLC, with the same results. The diastereoisomers of 6-trans- $\mathrm{LTB}_{4}$ and $\mathrm{LTB}_{4}$ eluted in solvent $\mathrm{I}$ at $19.0 \mathrm{~min}, 20.5$, and $24.9 \mathrm{~min}$, respectively. In solvent II, as assessed by $A_{234}$, a novel product incorporating radioactive counts from $\left[{ }^{3} \mathrm{H}\right] \mathrm{DCH}$ A eluted at $49.7 \mathrm{~min}$, distinct from the elution of a 5-HETE standard at $51.4 \mathrm{~min}$ (Fig. 7). A minor peak of radioactivity eluted at $56 \mathrm{~min}$, the retention time of the
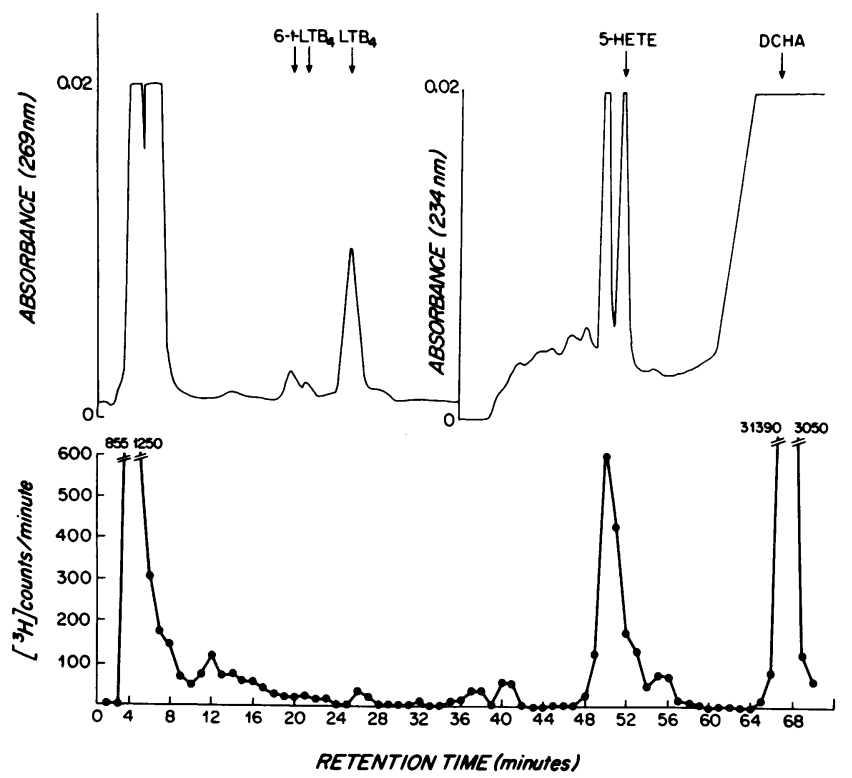

Figure 7. RP-HPLC of the supernatants from PMNs $\left(1 \times 10^{7}\right.$ cells $/ \mathrm{ml}$ ) activated by ionophore in the presence of $20 \mu \mathrm{g} / \mathrm{ml} \mathrm{DCHA}$ and $0.1 \mu \mathrm{Ci} / \mathrm{ml}\left[{ }^{3} \mathrm{H}\right] \mathrm{DCHA}$ analyzed by integrated UV absorbance and radioactivity.
4-hydroxy-DCHA standard. The products of the reaction with $\sim 40 \times 10^{7}$ activated cells were resolved by RP-HPLC, and the major DCHA-derived product eluting in solvent II was shown to have a $\lambda_{\max }$ at $234.2 \mathrm{~nm}$ (mean, $n=2$ ). The electron impact mass spectrum of the fully hydrogenated trimethylsilylether methyl ester derivative of this product yielded major mass ions at $313\left(\mathrm{M}^{+}-\mathrm{C}_{7} \mathrm{H}_{13} \mathrm{O}_{2}\right)$ and $231\left(\mathrm{M}^{+}-\mathrm{C}_{15} \mathrm{H}_{31}\right)$, indicating that the underivatized compound was 7-HDCHA.

Effects of exogenous DCHA on the generation of individual 5-lipoxygenase pathway metabolites from DCHA and endogenous arachidonic acid. $\left[{ }^{14} \mathrm{C}\right] \mathrm{AA}$-labeled PMNs $\left(1 \times 10^{7}\right.$ cells/ $\mathrm{ml}$ ) were activated by calcium ionophore in the absence and presence of increasing concentrations of DCHA and the products were resolved by RP-HPLC and quantitated by integrated UV absorbance (Fig. 8). The quantities of 5-HETE generated in the absence of DCHA, 303 $\pm 66 \mathrm{ng}$ (mean \pm SEM, $n=3$ ) were not consistently altered with increasing concentrations of DCHA, being $347 \pm 63 \mathrm{ng}$ at $5 \mu \mathrm{g} / \mathrm{ml} \mathrm{DCHA}$ and $291 \pm 45 \mathrm{ng}$ at $40 \mu \mathrm{g} / \mathrm{ml}$. DCHA. In contrast, there was a dose-related increase in the generation of $7-\mathrm{HDCHA}$ to $250 \pm 111 \mathrm{ng}$ (mean \pm SEM, $n=3$ ) at $40 \mu \mathrm{g} / \mathrm{ml} \mathrm{DCHA} \mathrm{(Fig.} 8 A$ ) such that the total production of monohydroxy products, as indicated by the sum of 5-HETE and 7-HDCA, increased from $303 \pm 66$ to $541 \pm 165 \mathrm{ng}$ at $40 \mu \mathrm{g} / \mathrm{ml}$ DCHA (Fig. $8 B$ ). The production of 6-trans-LTB $\mathrm{LB}_{4}$ was unaffected by incremental concentrations of exogenous DCHA, whereas the generation of $\mathrm{LTB}_{4}$ was minimally reduced from $250 \pm 51 \mathrm{ng}$ in the absence of DCHA to $148 \pm 35 \mathrm{ng}$ at $40 \mu \mathrm{g} / \mathrm{ml}$ DCHA (Fig. $8 B$ ).

Chemotactic activities of 5-HETE, 5-HEPE, and 7-HDCHA. The chemotactic activities of 5-HETE, 5-HEPE, and 7-HDCHA for human PMNs were compared with each other and with

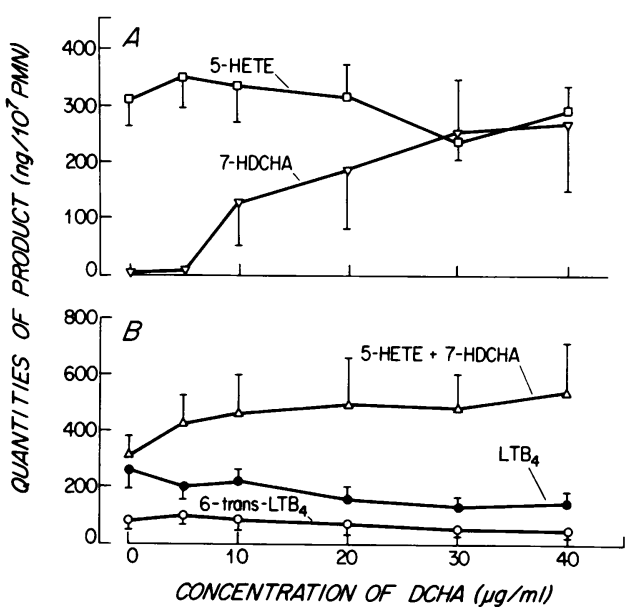

Figure 8. The effects of increasing concentrations of exogenous DCHA on the generation by ionophore-activated $\left[{ }^{14} \mathrm{C}\right] \mathrm{AA}$-labeled PMNs of 5-HETE and 7-HDCHA $(A)$ and of $\mathrm{LTB}_{4}$ and 6-trans-LTB $(B)$; the sum of 5-HETE and 7-HDCHA is also depicted in $B$. The results are the mean \pm SEM of three experiments. 
synthetic $\mathrm{LTB}_{4}$ in three separate assays (Fig. 9). $\mathrm{LTB}_{4}$ elicited a dose-related chemotactic response from $161 \pm 55 \mathrm{PMNs} / 5$ $\mathrm{hpf}($ mean $\pm \mathrm{SEM}, n=3)$ at $1 \mathrm{nM}$ to a plateau of $\sim 600 \mathrm{PMNs} /$ $5 \mathrm{hpf}$ at $0.1 \mu \mathrm{M}$. 5-HETE was inactive at $1 \mathrm{nM}$, attracted 131 PMNs/5 hpf at $50 \mathrm{nM}$, and elicited a maximum response of $216 \pm 50 \mathrm{PMNs} / 5$ hpf (mean $\pm \mathrm{SEM}, n=3$ ) at $100 \mathrm{nM}$. By interpolation, 5-HETE at a concentration between 50 and 100 $\mathrm{nM}$ would elicit a response equal to $1 \mathrm{nM} \mathrm{LTB}_{4}$, indicating that 5 -HETE was $1-2 \%$ as potent as $\mathrm{LTB}_{4}$. Furthermore, the maximum response to 5-HETE was only one-third that to $\mathrm{LTB}_{4}$. 5-HEPE and 7-HDCHA were inactive as chemotactic agents at all the dosages tested.

\section{Discussion}

EPA and DCHA, the most prominent of the fatty acids in a fish oil-enriched diet (38), are shown to differ not only in their suitability as exogenous substrates for the enzymes of the 5-lipoxygenase pathway of ionophore-activated human PMNs but also in their capacity to modulate the utilization of endogenous AA by the same pathway. Because the instability of human PMNs in culture does not permit the incorporation of substantial amounts of EPA and DCHA into the cell membrane, these alternative substrates were introduced exogenously in order to assess their effects on the metabolism of endogenous membrane-derived AA by ionophore-activated PMNs. The reactions were carried out in the presence of BSA to prevent re-esterification of the released products (39), and the fatty acid substrates were trace radiolabeled in the initial experiments to allow definition of products by their retention times relative to synthetic standards during RP-HPLC (Figs. 2 and 7). The products resulting from the oxidative metabolism of exogenous EPA and DCHA and endogenous AA by ionophore-activated cells were then quantitated by integrated UV absorbance during resolution of products by RP-HPLC and, in addition, for the tetraene and pentaene leukotrienes, by RIA of the eluate fractions. The profile of 5-lipoxygenase pathway products included: 5-HETE, 6-trans-LTB $4, \mathrm{LTB}_{4}$,

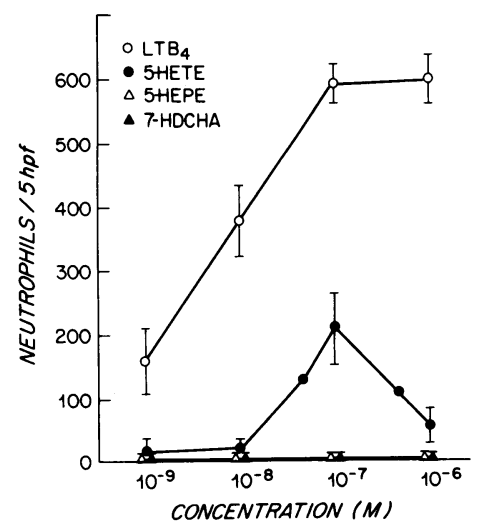

Figure 9. The chemotactic activities of synthetic $\mathrm{LTB}_{4}$ (O) and PMN-derived 5-HETE (๑), 5-HEPE $(\Delta)$, and 7-HDCHA ( () . Each point represents the mean \pm SEM of three separate assays with human PMNs from different donors performed in duplicate, except for $50 \mathrm{nM}$ and $500 \mathrm{nM}$ 5-HETE, which were the mean of two assays. and the sulfidopeptide tetraene leukotrienes derived from endogenous AA; 5-HEPE, 6-trans-LTB, $\mathrm{LTB}_{5}$, and the sulfidopeptide leukotrienes derived from EPA; and the predominant monohydroxy product, 7-HDCHA, derived from DCHA. The effect of the exogenous fatty acids on the generation of 5-lipoxygenase pathway products by activated human PMNs was quantitated for the eicosanoids of the tetraene series alone, for the sum of the tetraene and the pentaene eicosanoids, and for the sum of the tetraene and hexaene products. This approach permitted comparison of the two exogenous alternative fatty acids for their effects on the quantitative metabolism of endogenous AA by the 5-lipoxygenase pathway and for their associated suitability as simultaneous exogenous substrates.

Neither of the exogenous alternative substrate fatty acids nor exogenous AA in concentrations of $5-40 \mu \mathrm{g} / \mathrm{ml}$ altered the release of endogenous $\left[{ }^{14} \mathrm{C}\right] \mathrm{AA}$ from ionophore-activated human PMNs (Fig. 1). The dose-response effects of exogenous EPA on the oxidative metabolism of endogenous AA were different for 5-HETE and 6-trans-LTB ${ }_{4}$ than for $\mathrm{LTB}_{4}$. There was a twofold increase in 5-HETE with $10 \mu \mathrm{g} / \mathrm{ml}$ EPA along with an $\sim 50 \%$ increase in 6 -trans- $\mathrm{LTB}_{4}$; the generation of both products was suppressed with increasing doses of EPA, with 5-HETE production falling below base-line concentrations at 20 and $40 \mu \mathrm{g} / \mathrm{ml} \mathrm{EPA} \mathrm{(Fig.} 4 A$ ). In contrast, the generation of $\mathrm{LTB}_{4}$ was suppressed in a dose-related fashion, falling to half base-line values at $10 \mu \mathrm{g} / \mathrm{ml}$ EPA and being maximally suppressed at $20-40 \mu \mathrm{g} / \mathrm{ml}$. The stimulation of the 5-lipoxygenase by low dose EPA could reflect activation by the formation of a hydroperoxy intermediate, as has been reported for activation of the cyclooxygenase by its prostaglandin endoperoxide (1). This could be due to 5-hydroperoxy eicosapentaenoic acid formed either because EPA is the preferred substrate for the 5-lipoxygenase (40), or, less likely, because EPA is oxidized nonenzymatically by the generation of superoxide from the respiratory burst stimulated by the presence of exogenous fatty acids (41). The selective suppression of $\mathrm{LTB}_{4}$ formation was not due to a change in the time course of appearance of maximal amounts of $\mathrm{LTB}_{4}$ in the presence of EPA (Fig. 3) and was not due to an increase in the conversion of $\mathrm{LTB}_{4}$ to its $\omega$-oxidation metabolite (Table I). Presumably, an intermediate of EPA metabolism, such as LTA $_{5}$, down regulates preferentially the conversion of $\mathrm{LTA}_{4}$ to $\mathrm{LTB}_{4}$ by the epoxide hydrolase.

The incubation of $5 \mu \mathrm{g} / \mathrm{ml}$ of exogenous EPA with ionophore-activated PMNs generated 5-HEPE, whereas a concentration of $10 \mu \mathrm{g} / \mathrm{ml}$ was required for the appearance of 6-trans-LTB $\mathrm{LB}_{5}$ and $\mathrm{LTB}_{5}$. There was a further increase in

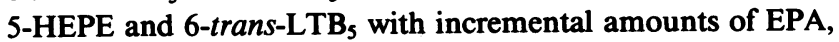
while the generation of $\mathrm{LTB}_{5}$ did not change significantly (Fig. $4 B$ ). The dose-response effects of exogenous EPA on the composite utilization of EPA and membrane-derived AA (Fig. $5 B$ ) again revealed a quantitative difference between the formation of the monohydroxy and the 6-trans-LTB $\mathrm{LB}_{4}$ products, as compared with the sum of $\mathrm{LTB}_{4}$ and $\mathrm{LTB}_{5}$. The additive 
generation of 5-HEPE and 5-HETE was maximal at $10 \mu \mathrm{g} / \mathrm{ml}$ and plateaued at twice the base-line concentrations from $20-40 \mu \mathrm{g} / \mathrm{ml}$. There was also an increase in the concentrations

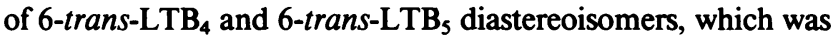
progressive throughout the dose range studied. In contrast, the additive generation of $\mathrm{LTB}_{4}$ and $\mathrm{LTB}_{5}$ decreased in a doserelated fashion to half the cumulative base-line levels at 30 $\mu \mathrm{g} / \mathrm{ml}$ EPA. Thus, the metabolism of exogenous EPA facilitated the oxidative metabolism of both EPA and endogenous AA to the monohydroxy and 6-trans-LTB products while decreasing the generation of the epoxide hydrolase products, $\mathrm{LTB}_{4}$ and LTB $_{5}$. The selective inhibition of the utilization of the intermediate epoxides by the epoxide hydrolase contrasts with their conversion by glutathionyl- $S$-transferase to the sulfidopeptide leukotrienes. Although the conversion of $\mathrm{LTA}_{4}$ to $\mathrm{LTC}_{4}$ in human PMNs is modest as compared with the formation of $\mathrm{LTB}_{4}$ (3), incremental concentrations of exogenous EPA permitted increased formation of $\mathrm{LTC}_{5}$, so that the sum of $\mathrm{LTC}_{5}$ and $\mathrm{LTC}_{4}$ from membrane-derived $\mathrm{AA}$ was greater than the formation of $\mathrm{LTC}_{4}$ in the absence of EPA (Fig. 6). That the inhibition of epoxide hydrolase activity is apparently due to a specific effect of exogenous fatty acid, especially EPA, is indicated by the dose-dependent effects of exogenous AA. Incremental concentrations of exogenous AA resulted in an increased production of 5-HETE and 6-trans-LTB $\mathrm{LB}_{4}$ by ionophore-activated human PMNs without a significant change in $\mathrm{LTB}_{4}$ generation (Fig. $5 \mathrm{~A}$ ). The progressive increase in the generation of 5-HETE by ionophore-activated PMNs in response to increasing exogenous AA concentrations contrasts with the generation of 5-HETE and 5-HEPE derived from membrane AA and exogenous EPA, respectively, in response to increasing concentrations of exogenous EPA (Fig. 5, $A$ and $B$ ). The sum of the 5-HETE and 5-HEPE generated was maximal at $10 \mu \mathrm{g} / \mathrm{ml}$ EPA and then plateaued from 20 to 40 $\mu \mathrm{g} / \mathrm{ml}$ EPA, suggesting that increasing concentrations of EPA limited the activity of the 5-lipoxygenase enzyme. There may well be two types of effects of exogenous EPA on the oxidative metabolism of endogenous AA by the 5-lipoxygenase pathway: dose-dependent stimulation and subsequent inactivation of 5-lipoxygenase by 5-HEPE, and selectively consistent inhibition of LTA $_{4}$ epoxide hydrolase by LTA $_{5}$.

The dose-response effect of exogenous DCHA on ionophoreactivated human PMNs was characterized by the predominant generation of 7-HDCHA and possibly minor quantities of 4-HDCHA (42). 7-HDCHA production began at $10 \mu \mathrm{g} / \mathrm{ml}$ DCHA and increased in amount so as to equal the concomitant formation of 5-HETE, which was unchanged by the presence of this exogenous alternative fatty acid (Fig. 8). Thus, in the presence of exogenous DCHA, the production of monohydroxy products increased to approximately two times base-line values at $40 \mu \mathrm{g} / \mathrm{ml}$. The production of 6-trans- $\mathrm{LTB}_{4}$ was unaffected by the incremental inputs of DCHA, whereas the generation of $\mathrm{LTB}_{4}$ was minimally reduced at 30 and $40 \mu \mathrm{g} / \mathrm{ml}$. Thus, as compared with EPA, DCHA did not stimulate membrane- derived AA metabolism at a low dosage, did not appreciably inhibit $\mathrm{LTB}_{4}$ formation, and was not a substrate suitable for the generation of leukotrienes. The apparent lack of competition by exogenous DCHA for utilization of endogenous AA may relate to its poor substrate function as compared with AA or EPA (40). Neither of the monohydroxy fatty acids of the alternative substrate fatty acids, 5-HEPE and 7-HDCHA, was biologically active as a chemotactic factor in an assay in which 5-HETE exhibited $\sim 2 \%$ of the potency of $\mathrm{LTB}_{4}$ (Fig. 9).

The respective capacities of EPA and DCHA to attenuate the oxidative metabolism of endogenous AA to pro-inflammatory products are distinctly different with regard to their action on the 5-lipoxygenase pathway, whereas both fatty acids are poor substrates and competitive inhibitors of the cyclooxygenase cascade (15-17). DCHA does not appreciably interfere with the metabolism of membrane-derived AA by ionophoreactivated PMNs and is not converted to leukotrienes, as was also observed in subcellular systems (17). The capacity of a fish oil enriched diet to attenuate the ex vivo production of $\mathrm{LTB}_{4}$ by ionophore-activated human neutrophils has been observed with an intake of 7 to $12 \mathrm{~g} \mathrm{EPA/d}$, combined with a restriction in dietary vegetable and animal fats in four volunteers for $3 \mathrm{wk}$; the neutrophils obtained after EPA consumption elaborated $25 \%$ less $\mathrm{LTB}_{4}$, as compared with that generated by neutrophils obtained in the pre-diet period. Production of LTB $_{5}$ was increased so that total generation of LTB compounds was not reduced (43). In contrast, in six volunteers receiving $4 \mathrm{~g}$ EPA for $4 \mathrm{wk}$ without additional alteration of their usual diets there was no suppression of $\mathrm{LTB}_{4}$ production; the ionophore-activated cells generated $\mathrm{LTB}_{4}$ and $\mathrm{LTB}_{5}$ in a ratio that corresponded to the representation of $\mathrm{AA}$ and EPA in the membrane phospholipids, suggesting that dosage may be an important determinant of the effects of EPA on the 5-lipoxygenase pathway (44). The conditions used in the present in vitro studies maximized the effects of EPA as an alternative fatty acid and demonstrated the dose-related suppression of $\mathrm{LTB}_{4}$ production.

\section{Acknowledgments}

This research was supported in part by grants AI-07722, AI-10356, AI-20081, HL-13262, HL-17382, and RR-05669 from the National Institutes of Health and in part by grants from The Hyde and Watson Foundation, the New England Peabody Home for Crippled Children, and the National Science Foundation. Dr. Lewis is a recipient of an Allergic Diseases Academic Award (AI-00399) from the National Institutes of Health.

\section{References}

1. Samuelsson, B., E. Goldyne, E. Granström, M. Hamberg, S. Hammarström, and C. Malmsten. 1978. Prostaglandins and thromboxanes. Ann. Rev. Biochem. 47:997-1029.

2. Borgeat, P., and B. Samuelsson. 1979. Arachidonic acid metab- 
olism in polymorphonuclear leukocytes: effects of ionophore A23187. Proc. Natl. Acad. Sci. USA. 76:2148-2152.

3. Weller, P., C. W. Lee, D. W. Foster, E. J. Corey, K. F. Austen, and R. A. Lewis. 1983. Generation and metabolism of 5-lipoxygenase pathway leukotrienes by human eosinophils: predominant production of leukotriene C4. Proc. Natl. Acad. Sci. USA. 80:7626-7630.

4. Williams, J. D., J. K. Czop, and K. F. Austen. 1984. Release of leukotrienes by human monocytes on stimulation of their phagocytic receptor for particulate activators. J. Immunol. 132:3034-3040.

5. Fels, A. O., N. A. Pawlowski, E. B. Cramer, T. K. C. King, Z. A. Cohn, and W. A. Scott. 1982. Human alveolar macrophages produce leukotriene B $_{4}$. Proc. Natl. Acad. Sci. USA. 79:7866-7870.

6. Martin, T. R., L. C. Altman, R. K. Albert, and W. R. Henderson. 1984. Leukotriene $B_{4}$ production by the human alveolar macrophage: a potential mechanism for amplifying inflammation in the lung. Am. Rev. Respir. Dis. 125:106-111.

7. McGlashan, D. W., P. Schleimer, S. P. Peters, E. S. Schulman, G. K. Adams, H. H. Newball, and L. M. Lichtenstein. 1982. Generation of leukotrienes by purified human lung mast cells. J. Clin. Invest. 70:747-751.

8. Patterson, N. A. M., S. I. Wasserman, J. W. Said, and K. F. Austen. 1976. Release of chemical mediators from partially purified human lung mast cells. J. Immunol. 117:1356-1362.

9. Borgeat, P., and B. Samuelsson. 1979. Metabolism of arachidonic acid in polymorphonuclear leukocytes: structural analysis of novel hydroxylated compounds. J. Biol. Chem. 254:7865-7868.

10. Borgeat, P., and B. Samuelsson. 1979. Arachidonic acid metabolism in polymorphonuclear leukocytes: unstable intermediate in the formation of dihydroxy acids. Proc. Natl. Acad. Sci. USA. 76:32133217.

11. Rådmark, O., C. Malmsten, B. Samuelsson, G. Goto, A. Marfat, and E. J. Corey. 1980. Leukotriene A: isolation from human polymorphonuclear leukocytes. J. Biol. Chem. 255:11828-11831.

12. Hammarström, S., and B. Samuelsson. 1980. Detection of leukotriene $A_{4}$ as an intermediate in the biosynthesis of leukotriene $C_{4}$ and $D_{4}$. FEBS (Fed. Eur. Biochem. Soc.) Lett. 122:83-86.

13. Borgeat, P., and B. Samuelsson. 1979. Transformation of arachidonic acid by rabbit polymorphonuclear leukocytes. Formation of a novel dihydroxyeicosatetraenoic acid. J. Biol. Chem. 254:26432646.

14. Murphy, R. C., S. Hammarström, and B. Samuelsson. 1979. Leukotriene $\mathrm{C}$ : a slow reacting substance from murine mastocytoma cells. Proc. Natl. Acad. Sci. USA. 76:4275-4279.

15. Needleman, P., A. Raz, M. S. Minkes, J. A. Ferendelli, and H. Sprecher. 1979. Triene prostaglandins: prostacyclin and thromboxane biosynthesis and unique biological properties. Proc. Nat. Acad. Sci. USA. 76:944-948.

16. Rao, G. H. R., E. Radha, and J. G. White. 1983. Effect of docosahexaenoic acid (DHA) on arachidonic acid metabolism and platelet function. Biochem. Biophys. Res. Commun. 117:549-555.

17. Corey, E. J., C. Shih, and J. R. Cashman. 1983. Docosahexaenoic acid is a strong inhibitor of prostaglandin but not leukotriene biosynthesis. Proc. Natl. Acad. Sci. USA. 80:3581-3584.

18. Goldman, D. W., W. C. Prickett, and E. J. Goetzl. 1983. Human neutrophil chemotactic and degranulating activities of leukotriene $\mathrm{B}_{5}\left(\mathrm{LTB}_{5}\right)$ derived from eicosapentaenoic acid. Biochem. Biophys. Res. Commun. 117:282-288.

19. Lee, T. H., J.-M. Mencia-Huerta, C. Shih, E. J. Corey, R. A. Lewis, and K. F. Austen. 1984. Characterization and biologic properties of 5,12-dihydroxy derivatives of eicosapentaenoic acid, including leukotrienes $\mathrm{B}_{5}$ and the double lipoxygenase product. J. Biol. Chem. 259:2383-2389.

20. Leitch, A. G., T. H. Lee, E. W. Ringel, J. D. Prickett, D. R. Robinson, S. G. Pyne, E. J. Corey, J. M. Drazen, K. F. Austen, and R. A. Lewis. 1984. Immunologically induced generation of tetraene and pentaene leukotrienes in the peritoneal cavities of menhaden-fed rats. J. Immunol. 132:2559-2565.

21. Terano, T., J. A. Salmon, and S. Moncada. 1984. Biosynthesis and biological activity of leukotriene $\mathbf{B}_{5}$. Prostaglandins. 27:217-232.

22. Hammarström, S. 1980. Leukotriene $C_{5}$ : a slow reacting substance derived from eicosapentaenoic acid. J. Biol. Chem. 255:70937094.

23. Dahlén, S. E., P. Hedqvist, and S. Hammarström. 1982. Contractile activities of several cysteine-containing leukotrienes in the guinea pig lung strip. Eur. J. Pharmacol. 86:207-215.

24. Corey, E. J., J. Albright, A. E. Barton, and S. Hashimoto. 1980. Chemical and enzymic syntheses of 5-HPETE, a key biological precursor of slow reacting substance of anaphylaxis (SRS-A), and 5-HETE. J. Am. Chem. Soc. 102:1435-1436.

25. Corey, E. J., A. Marfat, G. Goto, and F. Brion. 1980. Leukotriene B, total synthesis and assignment of stereochemistry. $J$. Am. Chem. Soc. 102:7984-7986.

26. Corey, E. J., A. Marfat, and D. Hoover. 1981. Stereospecific total synthesis of $12-(R)$ - and $12-(S)$ - forms of 6-trans-leukotriene B. Tetrahedron Lett. 22:1587-1590.

27. Corey, E. J., D. A. Clark, G. Goto, A. Marfat, C. Mioskowski, B. Samuelsson, and S. Hammarström. 1980. Stereospecific total synthesis of a slow reacting substance of anaphylaxis, leukotriene C. J. Am. Chem. Soc. 102:1436-1439.

28. Corey, E. J., D. A. Clark, A. Marfat, and G. Goto. 1980. Total synthesis of slow reacting substances. Tetrahedron Lett. 21:3143-3146.

29. Lewis, R. A., J. M. Drazen, K. F. Austen, A. Clark, and E. J. Corey. 1980. Identification of the $\mathrm{C}(6)-5$-conjugate of leukotriene $A$ with cysteine as a naturally occurring slow reacting substance of anaphylaxis. Importance of the 11-cis geometry for biological activity. Biochem. Biophys. Res. Commun. 96:271-277.

30. Corey, E. J., S. G. Pyne, and W.-G. Su. 1984. Total synthesis of leukotriene $B_{5}$. Tetrahedron Lett. 24:4883-4886.

31. Aveldano, M. I., and H. Sprecher. 1983. Synthesis of hydroxy fatty acids from $4,7,10,13,16,19-\left(1-{ }^{14} \mathrm{C}\right)$ docosahexaenoic acid by human platelets. J. Biol. Chem. 258:9339-9343.

32. Boyüm, A. 1968. Isolation of mononuclear cells and granulocytes from human blood. Scand. J. Clin. Invest. 21(Suppl. 97):77-89.

33. Lindgren, J. Å., G. Hansson, and B. Samuelsson. 1981. Formation of novel hydroxylated eicosatetraenoic acids in preparations of human polymorphonuclear leukocytes. FEBS (Fed. Eur. Biochem. Soc.) Lett. 128:329-335.

34. Hansson, G., J. Å. Lindgren, S.-E. Dahlén, P. Hedqvist, and B. Samuelsson. 1981. Identification and biological activity of noveloxidized metabolites of leukotriene $\mathrm{B}_{4}$ from human leukocytes. FEBS (Fed. Eur. Biochem. Soc.) Lett. 130:107-112.

35. Lewis, R. A., J.-M. Mencia-Huerta, R. J. Soberman, D. Hoover, A. Marfat, E. J. Corey, and K. F. Austen. 1982. Radioimmunoassay for leukotriene $B_{4}$. Proc. Nat. Acad. Sci. USA. 79:7904-7908.

36. Levine, L., R. Morgan, R. A. Lewis, K. F. Austen, D. A. Clark, A. Marfat, and E. J. Corey. 1981. Radioimmunoassay of the leukotrienes of slow reacting substance of anaphylaxis. Proc. Natl. Acad. Sci. USA. 78:7692-7696. 
37. Falk, W., R. H. Goodwin, and E. J. Leonard. 1980. A 48-well microchemotaxis assembly for rapid and accurate measurement of leukocyte migration. J. Immunol. Methods. 33:239-247.

38. Stansby, M. E. 1969. Nutritional properties of fish oils. World Rev. Nutr. Dietet. 11:46-105.

39. Stenson, W. F., and C. W. Parker. 1979. Metabolism of arachidonic acid in ionophore stimulated neutrophils. Esterification of a hydroxylated metabolite into phospholipids. J. Clin. Invest. 64:14571465.

40. Ochi, K., T. Yoshimoto, S. Yamamoto, K. Taniguchi, and T. Miyamoto. 1983. Arachidonate 5-lipoxygenase of guinea pig peritoneal polymorphonuclear leukocytes. J. Biol. Chem. 258:5754-5758.

41. Badwey, J. A., J. T. Curnutte and M. L. Karnovsky. 1981.
Cis-polyunsaturated fatty acids induce high levels of superoxide production by human neutrophils. J. Biol. Chem. 256:12640-12643.

42. Fischer, S., C. V. Schacky, W. Siess, Th. Strasser, and P. C. Weber. 1984. Uptake, release and metabolism of docosahexaenoic acid (DHA $\mathrm{C}_{22}: 6 \omega 3$ ) in human platelets and neutrophils. Biochem. Biophys. Res. Commun. 120:907-918.

43. Prescott, S. M. 1984. The effect of eicosapentaenoic acid on the leukotriene B pathway in human neutrophils. Proceedings of the n-3 Fatty Acid Meeting. Reading, England. 124-125.

44. Strasser, Th., S. Fischer, and P. C. Weber. 1984. Leukotriene $B_{5}\left(L_{T B}\right)$ is formed in human peripheral polymorphonuclear neutrophils (PMN) after dietary eicosapentaenoic acid (EPA). Proceedings of the n-3 Fatty Acid Meeting. Reading, England. 106-111. 